\title{
Microhabitat characteristics related to seasonal roost switching: implications from a threatened and introduced cockatoo species in an urban landscape
}

Sifeng Wang and L. M. Chu*

\begin{abstract}
Background: Communal roosting is a common avian social behaviour, which potentially provides foraging benefits, predation avoidance or thermoregulation in birds. To identify the crucial environmental factors associated with roost site selection, most studies have focused on the comparison of physical characteristics between roosts and nonroosts. However, the differences among roosts have usually been neglected and the causes of roost switching have seldom been investigated.
\end{abstract}

Methods: To explore the variations among roost sites and assess the most influential environmental factors related to seasonal roost switching, we conducted a 105-day observation on an introduced population of critically endangered Yellow-crested Cockatoo (Cacatua sulphurea) in an urban environment in Hong Kong from 2014 to 2016. We identified seven roost sites that were occupied in different seasons and then measured their microhabitat characteristics in terms of land use types, human disturbance and microclimate temperature. To quantify these differences, we used Pearson's chi-squared test, partial least squares determinant analysis (PLS-DA) and one-way repeated measures ANOVA, respectively.

Results: Our results distinguished roost sites occupied in three seasons, i.e. spring, summer and winter roosts, using several microhabitat characteristics. The land use types were significantly associated with roosts, where spring roosts were usually located in tree-dominated areas, which are the major feeding grounds. The discriminant analysis on human disturbance variables indicated that summer roosts were positively associated with night illumination. The microhabitat temperatures of winter roosts were significantly higher than those of most other roosts on cold nights.

Conclusions: The results highlighted significant variations among roosts, and seasonal roost switching was likely driven by specific microhabitat characteristics of each roost site, such as microclimate. It also helps us understand the behavioural adaptation of birds to urban environments.

Keywords: Communal roosting, Human disturbance, Land use, Microclimate, Seasonal variation

*Correspondence: leemanchu@cuhk.edu.hk

School of Life Sciences, The Chinese University of Hong Kong, Shatin, NT, Hong Kong SAR, China

\section{Background}

Communal roosting, commonly seen in birds, is the aggregation of more than two conspecifics spending the diurnal or nocturnal resting periods together (Bijleveld et al. 2010; Laughlin et al. 2014). However, the driving forces behind communal roosting and its adaptive value

(C) The Author(s) 2021. This article is licensed under a Creative Commons Attribution 4.0 International License, which permits use, sharing, adaptation, distribution and reproduction in any medium or format, as long as you give appropriate credit to the original author(s) and the source, provide a link to the Creative Commons licence, and indicate if changes were made. The images or other third party material in this article are included in the article's Creative Commons licence, unless indicated otherwise in a credit line to the material. If material is not included in the article's Creative Commons licence and your intended use is not permitted by statutory regulation or exceeds the permitted use, you will need to obtain permission directly from the copyright holder. To view a copy of this licence, visit http://creativeco mmons.org/licenses/by/4.0/. The Creative Commons Public Domain Dedication waiver (http://creativecommons.org/publicdomain/ zero/1.0/) applies to the data made available in this article, unless otherwise stated in a credit line to the data. 
are still not fully understood. Several hypotheses that explain the benefits of communal roosting have been proposed, including reduced thermoregulation demand, lower predation risk, and greater foraging efficiency (Eiserer 1984; Beauchamp 1999).

An increase in foraging efficiency is often considered as the main benefit of communal roosting in birds. Roost sites can act as information centres, whereby unsuccessful foragers can learn about the locations of food sources by following successful foragers (Ward and Zahavi 1973; Chou 2015). Locations where birds form roosts are often thought to be influenced by the proximity of food resources. Alternatively, the patch-sitting hypothesis proposes that roosts tend to be close to supplemental feeding areas, reducing the commuting cost from distant foraging sites to roost sites (Caccamise and Morrison 1986, 1988).

The thermoregulation hypothesis proposes that the presence of nearby companion birds can reduce high energy costs during inactivity phases (McKechnie and Lovegrove 2002; McKechnie et al. 2006), and/or the physical structure of the roost can protect the roosting birds from detrimental weather conditions (Broom et al. 1976). A considerable body of studies found that the microhabitat temperature of roost sites was higher than that of non-roost sites (Clergeau and Quenot 2007; Erickson 2015), which emphasised that roost site selection in cold weather may be constrained by thermoregulatory considerations (Buttemer 1985).

Many studies have demonstrated that the roosting behaviours of urban birds have strong associations with human activities, such as night light and land use (Khadraoui and Toews 2015; Daoud-Opit and Jones 2016; Saiyad et al. 2017). This could be attributed to predator avoidance, and specifically that roost sites found in urban areas with large open space and good illumination can aid the roosting birds in detecting their predators (Gorenzel and Salmon 1995; Peh and Sodhi 2002; Jaggard et al. 2015).

There has been a myriad of research aimed to find out the environmental factors influencing communal roosting by comparing the characteristics between roosts and non-roosts (Clergeau and Simonnet 1996; Peh and Sodhi 2002; Yap et al. 2002; Erickson 2015; Jaggard et al. 2015). However, some of these studies offered contradictory findings. For instance, both positive and negative impacts of illumination on roosting have been recorded (Erickson 2015; Jaggard et al. 2015). These inconsistent findings indicate that variations among roosts may be significant, but have been insufficiently studied. Only a few studies have emphasised the seasonal variation of roosts (Barrows 1981; Buehler et al. 1991; Gorenzel and Salmon 1995). Despite the enhanced understanding of roost site selection, knowledge regarding seasonal switching remains limited.

Yellow-crested Cockatoo (Cacatua sulphurea) is a critically endangered species endemic to Indonesia and Timor-Leste (BirdLife International 2018). As a result of the international pet trade, Yellow-crested Cockatoo was introduced to Hong Kong, China. A released and/or escaped population (c. 100-150 individuals) has inhabited the remnant green patches in highly urbanised areas (Leven and Corlett 2004; Mok et al. 2012). We observed that as many as 102 cockatoos formed communally roosting flocks throughout the year (Wang 2020). The birds would first come to a pre-roost gathering which is defined as an aggregation of individuals that occurs before departure to the nocturnal roosts (Moore and Switzer 1998). But while the pre-roost gathering was always in the same place, the locations of communal roosts changed seasonally. To some extent, this pattern supported the hypothesis that the function of pre-roost gathering is to provide individual birds with the knowledge about the changeable roost locations (Zahavi 1971; Sonerud et al. 2002). However, the causes of this seasonal variation of roost sites are not understood.

We hypothesised that the seasonal switching of roost sites was influenced by multiple environmental factors in an urban environment, and that roost sites would have different microhabitat characteristics. To test this, we assessed the microhabitat characteristics of roosts from three aspects: land use composition surrounding roost sites, microclimate temperature and human disturbance. We attempted to find out the crucial factors distinguishing different seasonal roosts and explore the possible causes of these associations. We hope that correlations between these environmental factors and roosts would contribute to the understanding of roost switching.

\section{Methods}

\section{Study site and roost sites}

The study was conducted in Hong Kong, which is located on the south coast of China $\left(22^{\circ} 09^{\prime}-22^{\circ} 33^{\prime} \mathrm{N}, 113^{\circ}\right.$ $\left.50^{\prime}-114^{\circ} 26^{\prime} \mathrm{E}\right)$. It is a compact and highly populated city, with the majority of 7.48 million population residing on only $24.4 \%$ of $1110 \mathrm{~km}^{2}$ total land (Planning Department 2020). Hong Kong has a humid subtropical monsoon climate, tending towards temperate for nearly half the year. Due to monsoons and typhoons, $80 \%$ of the precipitation is concentrated between May and September (Hong Kong Observatory 2020). The mean daily minimum temperature varies monthly, ranging from 14.6 to $26.9{ }^{\circ} \mathrm{C}$. In contrast, the native habitats of Yellow-crested Cockatoo in Indonesia are almost entirely tropical. The mean daily minimum temperature remains fairly constant throughout the year, averaging $23.2{ }^{\circ} \mathrm{C}$. The minimum 
temperature variations between Hong Kong and Indonesia are relatively greater between December and March than other months, with Hong Kong being $5.6^{\circ} \mathrm{C}$ to $8.6{ }^{\circ} \mathrm{C}$ colder during this season (Additional file 1 : Table S1). This indicates a possible night-time cold stress of Yellow-crested Cockatoo in the winter of Hong Kong.

The studied roosting flock, which can be regularly observed and easily tracked, assembles on the northern coast of Hong Kong Island. This district is a prime financial and commercial centre of the city, characterised by dense and tall buildings. It also contains two large urban parks, i.e. Hong Kong Park (8.2 ha) and Hong Kong Zoological and Botanical Gardens (5.6 ha), which are the major feeding grounds for Yellow-crested Cockatoo, providing abundant and various plant food sources (Fig. 1).

The roosting population was counted once a week in clear evenings for two years (Year 2014/15 and 2015/16) from March 2014 to March 2016. As the evening progressed, birds in pairs or small flocks successively flew into the pre-roost gathering sites in Hong Kong Park from all directions. The observation lasted from late afternoon to early evening, beginning when the individuals flew to the pre-roost aggregation sites until no conspicuous flying and calling came from the flock at the final roost site (Davis 1955). We located the birds visually using binoculars (Nikon Monarch 5, $10 \times 42$ ), standing at a 30-m high observation tower in Hong Kong Park (Fig. 1). The observation tower afforded an unobstructed view to track the birds as they entered the pre-roost gathering sites and then settled into the roost sites, with a few exceptional locations where the birds could not be seen but their presence could later be identified by faecal droppings (Gorenzel and Salmon 1995). The number of cockatoos attending the pre-roost aggregation was counted every 5 min until the cockatoos flew into their roost site(s). The roosting flock size was counted at the roost site; otherwise, it was estimated from the final number obtained at the pre-roost site when not all individuals could be distinguished at the roost site. The pre-roosting aggregation would sometimes split up to occupy two to three roost sites, that the one greater in number was regarded as the major roost while the others were minor roosts.

In total, seven roost sites were identified to be used by Yellow-crested Cockatoo during the 105 observational

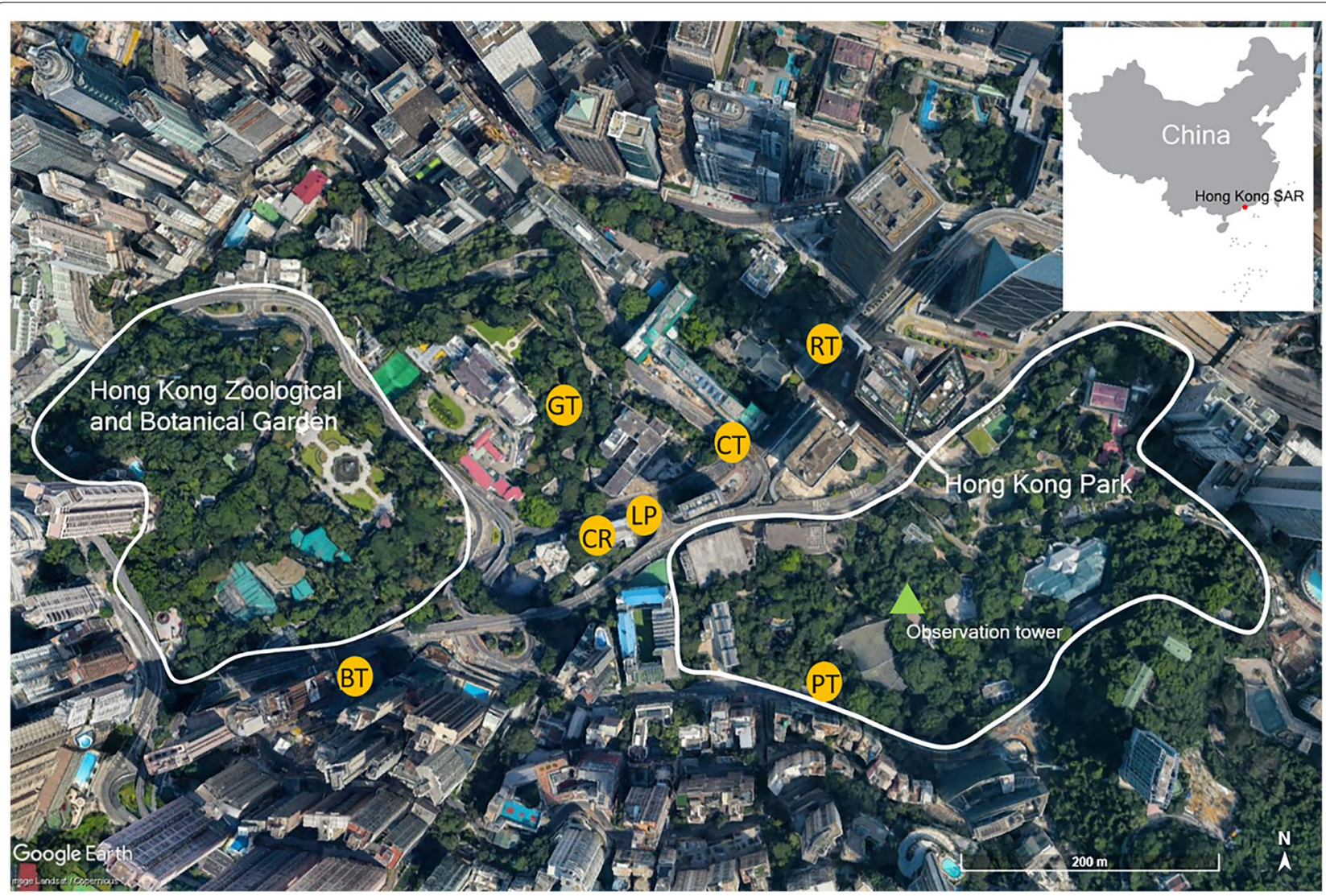

Fig. 1 Map showing the seven roost sites (yellow circles with roost names) among those high-rises and the two adjacent urban parks (Map source: Google Earth image $\odot ~ 2019)$ 
days. Five sites were located on trees (BT, CT, GT, PT and $\mathrm{RT}$ ), one on a building roof (CR), and the other on a cluster of lamp posts (LP). Given the occupied months and night minimum air temperature of occupied days of each roost (Additional file 2: Fig. S1), we classified the roost sites into three distinct groups, i.e. spring roosts (GT and PT), summer roosts (BT, CR and LP), and winter roosts (CT and $\mathrm{RT}$ ). As roost $\mathrm{CR}$ was not accessible, we excluded it from all microhabitat-related analyses.

\section{Data collection}

To investigate whether land use around roosts affects roost site selection, we measured the proportion of land use types within a 50-m radius plot around each roost delineated by Google Earth Pro (Google Inc.). We modified the classification of land uses defined by Yap et al. (2002), whereby "tree-dominated area" refers to lands covered by tree canopies, "built-up area" represents developed areas with buildings, and "open space" consists of areas covered by roads, low-growing vegetation or other vacant lands.

To explore the level of human disturbance of each roost site, we quantified human disturbance using multiple anthropogenic components (Gorenzel and Salmon 1995; Peh and Sodhi 2002; Yap et al. 2002; Jaggard et al. 2015). Specifically, we collected data on (1) pedestrians: nighttime occurrence of pedestrians passing by the roosts in 10-min durations; (2) traffic: night-time car volume on the nearest roads to the roosts in 10-min durations; (3) night-time noise level at the roost sites; (4) nighttime light intensity at the roost sites; (5) mean roosting height above ground; and (6) distance to the nearest main road, building, streetlight and tree. We measured the mean number of pedestrians and number of vehicles of each roost by conducting a 10-min survey soon after the roosting flock settled down, once a month from July 2015 to February 2016. Similarly, we measured the noise levels and light intensity once a month, using an extendable sound meter and light meter, respectively. We held the instruments at the roosting height at four directions around each roost, soon after the roosting flock settled down. We recorded the light intensity three times per sampling evening and the average decibel for a total of 5 -min per sampling evening. We measured the mean roosting height using a rangefinder (Nikon Forestry Pro). We estimated the distance to the nearest main road, building, streetlight, and tree on the Hong Kong GEOINFO MAP (www.map.gov.hk/gm/) since the measurements could not be accurately made on the ground. The mean values of the anthropogenic disturbance variables are given in Additional file 1: Table S1.

As described above, the night-time temperature in the winter of Hong Kong is much lower than that in the native habitats of Yellow-crested Cockatoo. We measured the microclimate of each roost site when the winter roosts were occupied, and recorded the microhabitat temperature at each roost site by positioning a thermometer on an extendable pole at the roosting height. The temperature was recorded for $5 \mathrm{~min}$ soon after the roosting flock settled down on each roost on 12 randomly selected days from late November 2015 to January 2016, from which the mean values $\left(T_{\text {micro }}\right)$ were calculated.

\section{Data analysis}

We compared the roosting flock size of each roost site using Kruskal-Wallis test followed by Wilcoxon rank sum tests. We conducted Pearson's chi-squared test to determine whether roost sites and land use types were independent of each other. We used Pearson residuals to measure the discrepancy between observed and expected values (Friendly 1994; Friendly and Meyer 2015). The formula is:

Pearson residual $=($ actual - expected $) / \sqrt{\text { expected }}$

Cut-off points of Pearson residuals at \pm 2 and \pm 4 implied that the residuals were significant at $\alpha=0.05$ and $\alpha=0.0001$ levels respectively (Meyer et al. 2006). We performed a hierarchical clustering analysis using Ward's method to investigate how the roosts were grouped by human disturbance variables. Thereafter, we performed a partial least squares determinant analysis (PLS-DA) to maximise the variation between seasonal roost groups and identify the type of human disturbance important in roost site selection. PLS regression is designed explicitly for analytical situations where predictor variables are highly correlated and/or the sample size is smaller than the number of observations (Carrascal et al. 2009). The special case of PLS-DA is a supervised method where the response is a categorical variable (Pérez-Enciso and Tenenhaus 2003), like the seasonal roost pattern in the present study. This method extracts components (or latent variables) from predictor variables and indicates its importance in explaining the response variable. The results of the PLS-DA model include R2X and R2Y scores which indicate the explained variance and Q2Y score which indicates the predictive variance of model fit (Wu and Guo 2018). The performance of PLS-DA model was assessed via overall misclassification error rate and significance of R2Y and Q2Y by leave-one-out cross-validation and permutation testing (100 cycles) respectively (Thévenot et al. 2015; Rohart et al. 2017). The predictor variables were standardised before PLS-DA regression. We performed a one-way repeated measures ANOVA followed by paired $t$-tests to determine whether there was a significant difference of microclimate temperature 
between winter roosts and other roosts. We conducted the Mauchly's test of sphericity to test if the variances of each paired roost site were equal and assumption of sphericity was met. Prior to the analysis, $T_{\text {micro }}$ values were standardised to eliminate the variation among sampling times.

We used R version 3.5.1 (R Core Team 2018) to conduct the statistical analyses. Prior to statistical analyses, we checked the data normality by Shapiro-Wilk normality tests and homogeneity of variance by $F$-tests. We used the car package (Fox and Weisberg 2019) for oneway repeated measures ANOVA, vcd package (Meyer et al. 2017) for Pearson chi-squared test and mosaic plot (Friendly 2013), ggtern package (Hamilton and Ferry 2018) for ternary diagram, cluster and factoextra packages (Kassambara et al. 2017; Maechler et al. 2019) for clustering analysis, and ropls and mixOmics packages (Thévenot et al. 2015; Rohart et al. 2017) for PLS-DA analysis.

\section{Results}

\section{Usage of roost sites}

BT was the most frequently used roost $(44.8 \%$ of total observation days), followed by CT (23.8\%), PT (16.2\%) and RT (15.2\%); LP, CR, and GT were the least frequently used (Fig. 2a). Winter roosts CT and RT were usually occupied between November and March. Specifically, CT was mainly occupied in the first year, while RT was mostly used in the second year. Likewise, spring roost PT was primarily used in 2014/5 whereas GT was used more in 2015/6. PT was often used between March and June, but GT was only occupied between April and May. The occupancy of summer roost BT lasted for 8 months, from April to November. In contrast, summer roosts CR and LP were usually occupied between June and September, and on most occasions, they were used as the minor roosts for $\mathrm{BT}$. At the time of seasonal roost switching, the roosts of the last season and next season were sometimes used interchangeably. This implied that the environmental factors affecting roost switching had been changing but were not stable, and cockatoos were sensitive to these changes by choosing the optimal roost site on a daily basis.

In terms of roosting flock size, the differences among BT, CT, GT, PT and RT were not significant, with a mean flock size ranging from 63 to 74 . However, the mean roosting flock size of CR and LP was 21 and 22, respectively, which were significantly smaller than those of other roosts (Kruskal-Wallis test, $\chi^{2}=37.008, \mathrm{df}=6$, $p<0.001)$. This is because these sites were artificial perching structures with limited space. Violin plots showed the data distribution of flock size of each roost, where the wider sections of the violin plots represented a higher

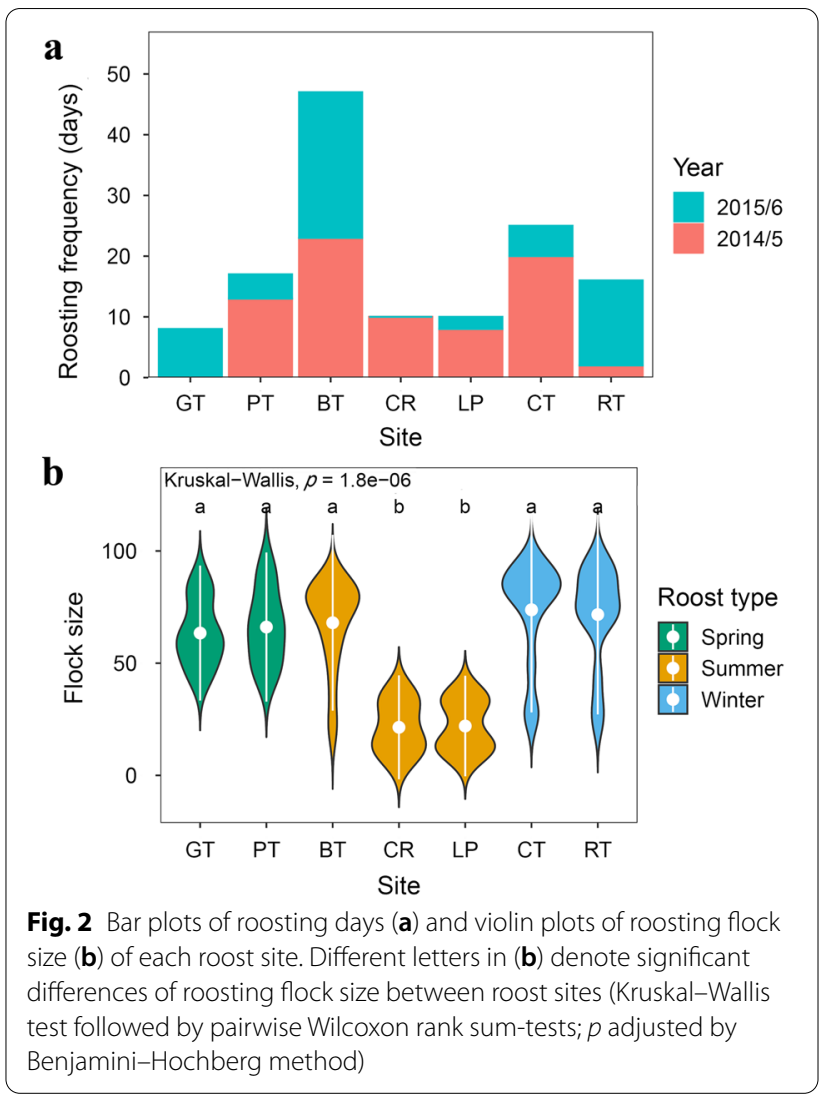

probability of that flock size and vice versa (Fig. 2b). With the exception of BT, the distribution of the data was similar within seasons, but different across seasons. For example, the flock size was around the median for spring roosts GT and PT, while the distribution of flock size of summer roosts CR and LP had two noticeable peaks. It indicated that variations in flock size were larger for roosts used in different seasons than those used in the same season.

\section{Microhabitat characteristics of roost sites}

Land use types were significantly associated with roost sites (Pearson's chi-squared test, $\chi^{2}=130.82, \mathrm{df}=10$, $p<0.001)$. As indicated by the Pearson residuals, treedominated areas were strongly positively associated with spring roosts GT and PT (Fig. 3a), with a proportion of $50 \%$ and $63 \%$ respectively (Fig. 3b). In contrast, treedominated areas were significantly negatively related to summer roost BT (18\%) and LP (14\%), and winter roost CT (15\%). The proportion of tree-dominated areas separated the roosts used during spring from the other roosts (Fig. 3b). This indicated that spring roosts were closer to green patches than other roosts. Overall, the amount of built-up area varied considerably; for example, the percentage of built-up area was extremely low surrounding 

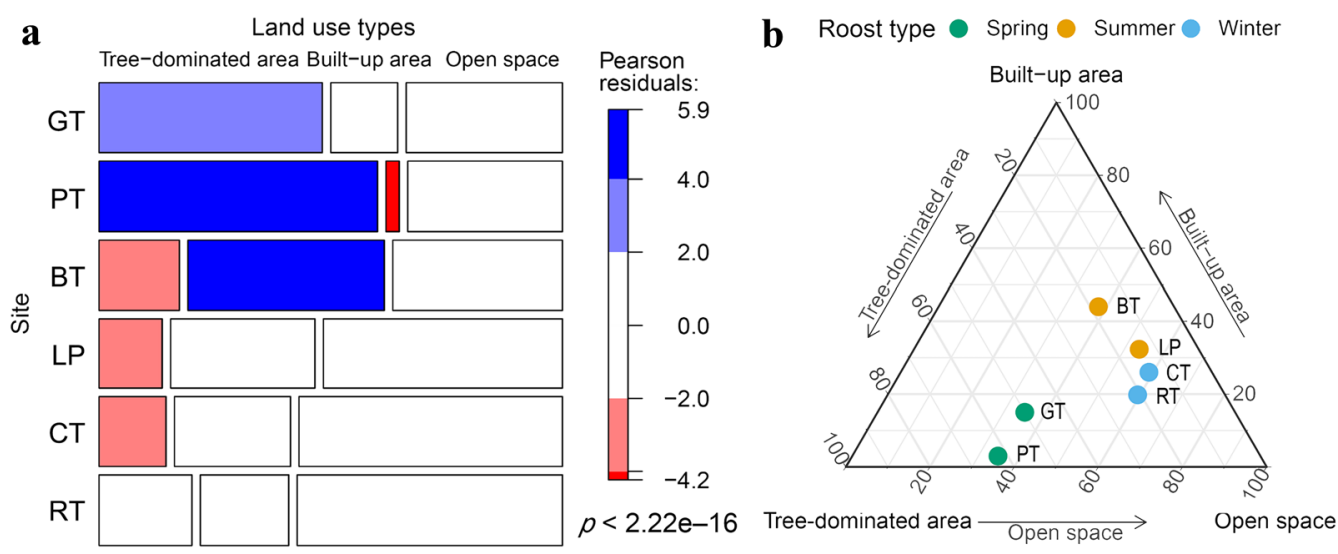

Fig. 3 A mosaic plot (a) with residual-based shading of land use types versus roost sites, and a ternary diagram (b) of the proportion of land use types within a 50-m circular plot of roost sites. In the mosaic plot, blue colour indicates the observed value is higher than the expected value, while red colour denotes the observed value is lower than the expected value

spring roost PT (3\%) but was much larger for summer roost BT (44\%).

The seasonal roost categories were well distinguished by the cluster analysis using anthropogenic disturbance parameters (Fig. 4a). This suggests that human disturbance was associated with seasonal switching among roosts. Moreover, two components (Comp 1 and Comp 2) extracted from the PLS-DA regression were sufficient to achieve the best classification performance of roosts by cross-validation (Overall error rate $=0.000$ ) and permutation testing $(p=0.04)$. They captured $73.6 \%$ of the human disturbance variables and explained $98.4 \%$ of the variance of seasonal roost types (Table 1). Performance of the prediction was good with a cumulative predict variance (Q2Y) of $89.1 \%$. Comp 1 discriminated spring roosts (PT and GT) from other roosts (Fig. 4b), where the distance to the nearest building, streetlight and road were positively correlated with spring roosts while traffic, noise level, pedestrians and light intensity had negative loadings on spring roosts (Fig. 4c, d). Consistent with the analyses on land use types, spring roosts were much closer to other trees. These indicated that spring roosts were distant from all human activities. Comp 2 further discriminated winter and summer roosts (Fig. 4b). Both roost groups were close to building, light and road. However, winter roosts were positively associated with roosting height, pedestrians, and noise level, where they were usually near bus stops, zebra crossings, and a tourist service centre. Summer roosts were positively related to light intensity (Fig. 4c, e).

Roosts were categorised into two distinct groups by $T_{\text {micro }}$, viz. the high and low $T_{\text {micro }}$ group, that exhibited a highly significant difference (one-way repeated measures ANOVA, sphericity assumed, $F(5,55)=37.6, p<0.001$;
Fig. 5). The temperature difference between groups attained as much as $1.1{ }^{\circ} \mathrm{C}$, where the high $T_{\text {micro }}$ group included CT, RT and LP, and the low $T_{\text {micro }}$ group comprised of BT, GT and PT. Winter roosts were all categorised into the high $T_{\text {micro }}$ group, which were significantly warmer than the spring roosts and the major summer roost. It might be because winter roosts are close to the main road with heavy traffic and pedestrians (Additional file 1: Table S2), from which the external source of heat was produced.

\section{Discussion}

Seasonal switching of roost sites was associated with multiple environmental factors, wherein some microhabitat characteristics showed consistency among roost sites used in the same season but significant differences among sites used in different seasons.

Spring roosts were distinguished from other roosts by the high proportion of canopy cover at and adjacent to the roost sites. Besides, spring roosts were farther away from the main roads, streetlights, and buildings. This indicates that spring roosts were closer to green patches than other roosts. In addition, these related green patches are urban parks which serve as the daily feeding grounds and diurnal activity centre for Yellow-crested Cockatoo (Wang et al. 2018). A handful of research had shed light on the importance of food resources in roost site selection and shown that roost sites are usually located in the most visited foraging areas (Jenni 1991; Yap et al. 2002; Saiyad et al. 2017). Caccamise and Morrison (1988) found an increase in the number of European Starling using major roosts coincided with seasonal changes in foraging-substrate selection and diet composition. However, the information centre hypothesis may not apply to 
a

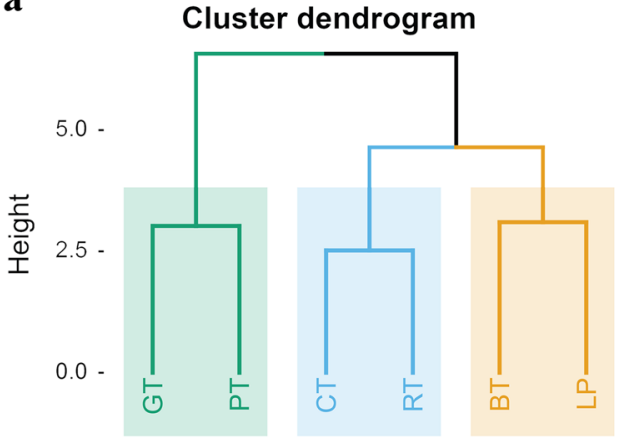

b

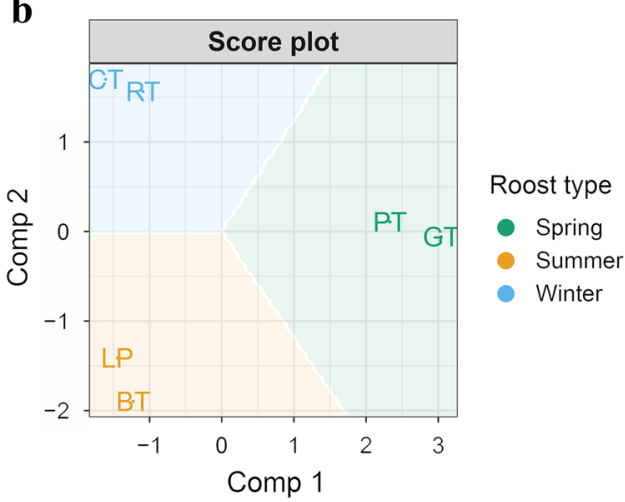

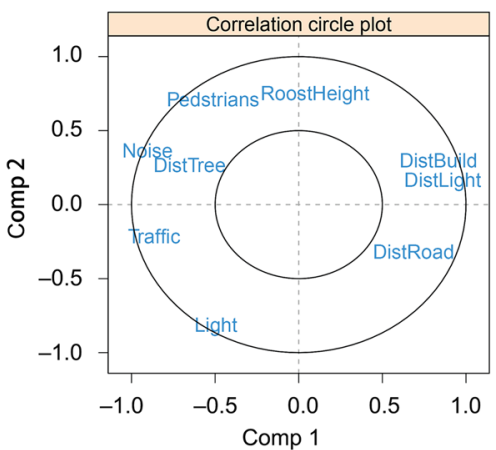

d

Contribution on Comp 1

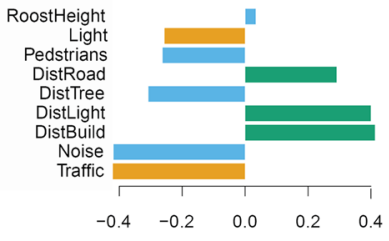

$\mathbf{e}$
Contribution on Comp 2

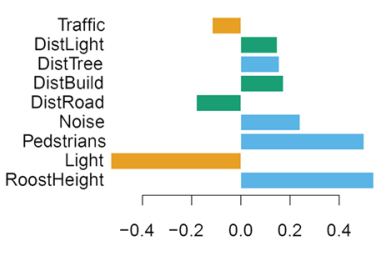

Fig. 4 Hierarchical dendrogram using Ward's clustering method (a), and PLS-DA regression score plot (b), correlation circle plot (c) and loading plots $(\mathbf{d}, \mathbf{e})$ of anthropogenic disturbance parameters on seasonal roost patterns. The score plot visualises the component scores, and prediction areas of each roost category. The correlation circle plot displays the Pearson correlation between the variables and latent components. The loading plots show the loading weights (contributions) of each variable on each component. The most important variables (according to coefficient values) are ordered from bottom to top. Colours indicate the seasonal roost pattern where the mean value of this variable is maximal. Roost Height: roosting height; Light: light intensity; Noise: noise level; DistRoad/DistTree/DistLight/DistBuild: distance to the nearest road/tree/light/building

Table 1 Percentage of explained variance in the predictor variables (R2X) and the response variable (R2Y) per component and their cumulative values (R2X cum and R2Y cum) derived from PLS-DA regression

\begin{tabular}{lllllll}
\hline Component & R2X & R2X cum & R2Y & R2Y cum & Q2Y cum & Error rate \\
\hline Comp 1 & 0.491 & 0.491 & 0.491 & 0.491 & 0.165 & 0.833 \\
Comp 2 & 0.245 & 0.736 & 0.494 & 0.984 & 0.891 & 0.000 \\
\hline
\end{tabular}

Q2Y cum is the cumulative predictive variance of fit by cross-validation. Error rate using maximum distance in Comp 2 includes the performance of the PLS-DA model in Comp 1

this study as the locations of food sources (e.g. plants) did not change dramatically in the short-term.

Summer roosts were often located in less vegetated areas but surrounded by a larger proportion of built-up and open area. Besides, night light had a positive correlation on roosting in summer for Yellow-crested Cockatoo. Rainbow Lorikeet (Trichoglossus haematodus) and Carnaby's Black Cockatoo (Calyptorhynchus latirostris) had similar preference for roost sites in parking lots and sports grounds that received more artificial light at night (Berry 2008; Jaggard et al. 2015; Daoud-Opit and Jones
2016; Le Roux 2017). The roosts of House Crow (Corvus splendens) in mid-July to mid-October in metropolitan Singapore had better illumination, shorter distance to buildings, and less surrounding vegetation (Peh and Sodhi 2002), a result which was very similar to the urban setting of the summer roosts of Yellow-crested Cockatoo in this study. It is generally acknowledged that light is associated with predator avoidance because parrot species have relatively poor vision in low-light conditions (Birkhead 2012). New-borns of Yellow-crested Cockatoo were often observed in the roost sites. Indeed, roost 


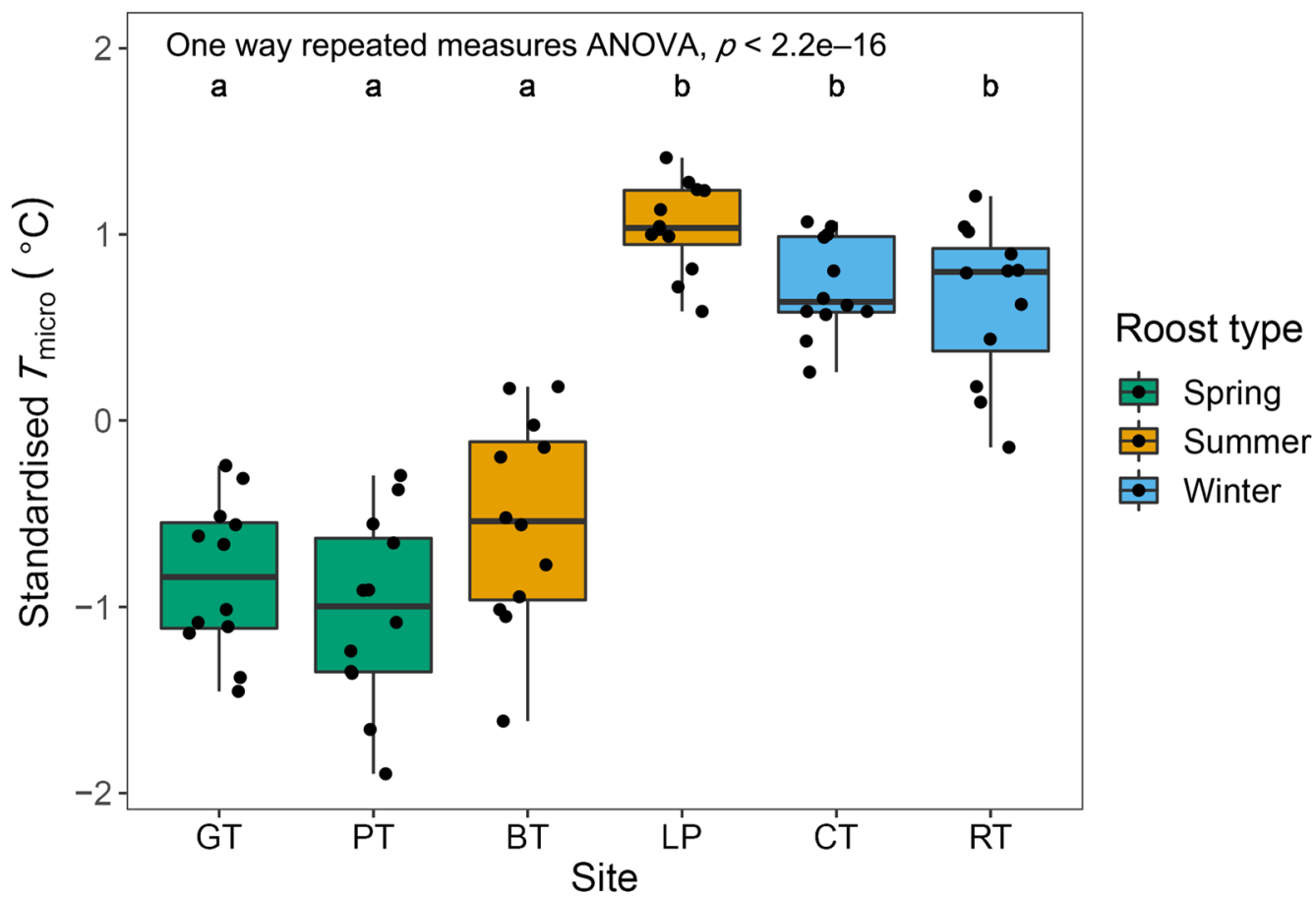

Fig. 5 Boxplots of standardised $T_{\text {micro }}$ of each roost site. Different letters denote significant differences of $T_{\text {micro }}$ between roost sites (one-way repeated measures ANOVA followed by paired pairwise $t$-tests; $p$ adjusted by Benjamini-Hochberg method)

switching in summer was probably related to the protection of juveniles because they were likely to be vulnerable to some commonly seen urban predators (e.g. wild cats, masked palm civets).

Winter roosts were characterised by higher microhabitat temperatures, which suggests a preference for relatively warmer roost sites in cold weather. Similar studies found that the minimum temperature was usually $0.5{ }^{\circ} \mathrm{C}$ to $1.4{ }^{\circ} \mathrm{C}$ greater at roosts compared to nonroosts for American Crow (Corvus brachyrhynchos) and European Starling (Sturnus vulgaris) in an urban environment (Gorenzel and Salmon 1995; Clergeau and Quenot 2007; Erikson 2015). The mean temperature of Hong Kong is $6{ }^{\circ} \mathrm{C}$ to $9{ }^{\circ} \mathrm{C}$ lower than that in Indonesia between November to April, which is an indication of their behavioural flexibility that Yellow-crested Cockatoo coped with low-temperature stress in a non-native urban environment. Switches between roosts over a short period also highlight that Yellow-crested Cockatoo is sensitive to abrupt temperature changes. During late November to early December 2015, the cockatoos started to roost on the winter roost RT when the ambient temperature dropped to $15.9^{\circ} \mathrm{C}$, but they returned quickly to the summer roost $\mathrm{BT}$ as soon as the ambient temperature increased to $22.0^{\circ} \mathrm{C}$. After a few days, they switched back to the winter roost again when cold weather prevailed.
The warm roosts were usually associated with intensive human activities because the concrete substrate beneath and urban heat island effect is an external source of heat for the roosts (Clergeau and Quenot 2007; Le Roux 2017). Due to urban heat island effect, the temperature in commercial areas is usually greater than residential areas and urban parks (Lee et al. 2009), which is consistent with land uses composition for roost sites in this study. For example, Asian Rose-necked Parakeet (Alexandrinus manillensis) roosted in the warmest places in cities where traffic was highest (Braun et al. 2018). American Crow preferred roosting in commercial areas and along streets, where the interior canopy temperatures of the roost trees were higher (Gorenzel and Salmon 1995). Likewise, the winter roosts of Yellow-crested Cockatoo were characterised by high levels of noise and pedestrian flow under the roost trees, as well as a short distance to the main road with heavy traffic.

Our results confirmed that differences in microhabitat characteristics among seasonal roosts could be significant. Consequently, it was not surprising that some studies, focusing on variations between roosts and nonroosts, have obtained inconsistent results with ours. For example, Erickson (2015) found that the night-time light intensity was lower at roosts than that at non-roosts probably because they only investigated the winter 
roosts. Clergeau and Quenot (2007) found ambient temperature but not illumination significantly higher in the roost site, perhaps as they only studied the roosts from November to February. In contrast, our results indicated that illumination was possibly just not the major selective factor for birds during this period. Despite these inconsistencies with previous work, which may be the result of habitat differences at the species level, our study provides an alternative explanation for variation among roost sites between which birds can seasonally switch.

This study was limited by the small sample size. Cockatoos (c. 20-30 individuals) outside the study area were not surveyed due to their small flock size and unstable roosting behaviour observed. Another limitation was that the results based on correlation analyses were not robust to support any hypothesis related to the benefits and driving forces behind communal roosting. Sampling size could be increased by identifying other relatively stable roosting flocks in Hong Kong or studying urban populations in other countries such as Singapore (Neo 2012). Besides, future studies can be designed to explain the specific requirements for roost sites in different seasons.

\section{Conclusions}

Roost site switching is the result of the selection of different environmental factors in different seasons. Spring roosts were close to green patches, and distant from the main roads, streetlights and buildings. Summer roosts usually received more artificial light in less vegetated areas. Winter roosts had higher microhabitat temperatures, usually being isolated tall trees located in the most crowded and noisiest urban areas. The study provides evidence that the variations among roost sites were associated with differences in microhabitat characteristics and suggests that special attention should be paid to the seasonal variation among roost sites in future studies.

\section{Supplementary Information}

The online version contains supplementary material available at https://doi. org/10.1186/s40657-021-00270-9.

Additional file 1: Table S1. The difference of mean daily minimum temperature $\left(I_{\min }\right)$ between Hong Kong $\left(T_{\min }, H K\right)$ and five locations of Indonesia $\left(T_{\mathrm{min}}\right)$, respectively. Table $\mathbf{S 2}$. Mean values and standard deviations (if any) of anthropogenic disturbance variables of roost sites of Yellow-crested Cockatoo in urban areas of Hong Kong.

Additional file 2: Figure S1. Boxplots of the $T_{\text {ambient }}$ (night minimum air temperature of occupied days) of each roost site during the study period. Different letters denote significant differences between roost sites (Kruskal-Wallis test followed by pairwise Wilcoxon rank sum tests; $p$ adjusted by Benjamini-Hochberg method).

Acknowledgements

We thank Mr. Ben Yeung and Mr. Banson Leung for their technical assistance.

\section{Authors' contributions}

LMC and SW conceived the idea. SW collected and analysed the data, and leaded the writing. LMC revised and polished the manuscript. Both authors read and approved the final manuscript.

\section{Funding}

This study was supported by the Hong Kong Environment and Conservation Fund (ECF Project 02/2014) and the United College Endowment Fund of The Chinese University of Hong Kong.

\section{Availability of data and materials}

The datasets used and/or analysed during the current study are available from the corresponding author on reasonable request.

Ethics approval and consent to participate

Not applicable.

Consent for publication

Not applicable.

Competing interests

The authors declare that they have no competing interests.

Received: 22 November 2020 Accepted: 18 June 2021

Published online: 28 June 2021

\section{References}

Barrows CW. Roost selection by spotted owls: an adaptation to heat stress. Condor. 1981:83:302-9.

Beauchamp G. The evolution of communal roosting in birds: origin and secondary losses. Behav Ecol. 1999;10:675-87.

Berry PF. Counts of Carnaby's Cockatoo (Calyptorhynchus latirostris) and records of flock composition at an overnight roosting site in metropolitan Perth. West Aust Nat. 2008;26:1-11.

Bijleveld Al, Egas M, van Gils JA, Piersma T. Beyond the information centre hypothesis: communal roosting for information on food, predators, travel companions and mates? Oikos. 2010;119:277-85.

BirdLife International. Yellow-crested Cockatoo Cacatua sulphurea. The IUCN Red List of Threatened Species 2018: e.T22684777A131874695. 2018. https://doi.org/10.2305/IUCN.UK.2018-2.RLTS.T22684777A131874695.en. Accessed 09 Oct 2020.

Birkhead T. Bird sense: what it's like to be a bird. London: Bloomsbury Publishing; 2012.

Braun MP, Braun N, Franz D, Groß B, Dreyer W, Laucht S, et al. Effects of cold winters and roost site stability on population development of non-native Asian ring-necked parakeets (Alexandrinus manillensis) in temperate Central Europe - results of a 16-year census. Eur J Ecol. 2018;4:49-55.

Broom DM, Dick WJA, Johnson CE, Sales DI, Zahavi A. Pied wagtail roosting and feeding behaviour. Bird Study. 1976;23:267-79.

Buehler DA, Mersmann TJ, Fraser JD, Seegar JK. Winter microclimate of bald eagle roosts on the northern Chesapeake Bay. Auk. 1991;108:612-8.

Buttemer WA. Energy relations of winter roost-site utilization by American goldfinches (Carduelis tristis). Oecologia. 1985;68:126-32.

Caccamise DF, Morrison DW. Avian communal roosting: implications of diurnal activity centers. Am Nat. 1986;128:191-8.

Caccamise DF, Morrison DW. Avian communal roosting: a test of the "patchsitting" hypothesis. Condor. 1988;90:453-8.

Carrascal LM, Galván I, Gordo O. Partial least squares regression as an alternative to current regression methods used in ecology. Oikos. 2009;1 18:681-90

Chou M. American Crow (Corvus brachyrhynchos) flight behavior from communal foraging sites to communal roosting sites in Yolo County, California. UC Davis Undergraduate Res J. 2015;17:1-9.

Clergeau P, Quenot F. Roost selection flexibility of European starlings aids invasion of urban landscape. Landscape Urban Plan. 2007;80:56-62.

Clergeau P, Simonnet E. Microclimate in communal roost sites of starlings Sturnus vulgaris. J Ornithol. 1996;137:358-61. 
Daoud-Opit S, Jones DN. Guided by the light: roost choice and behaviour of urban Rainbow Lorikeets (Trichoglossus haematodus). Eur J Ecol. 2016:2:72-80

Davis DE. Population changes and roosting time of starlings. Ecology. 1955;36:423-30

Eiserer LA. Communal roosting in birds. Bird Behav. 1984;5:61-80.

Erickson AD. A multi-scaled analysis of urban American crow (Corvus brachyrhynchos) winter roost characteristics in Minnesota. University of Minnesota Digital Conservancy. 2015. http://hdl.handle.net/11299/171957. Accessed 09 Oct 2020.

Fox J, Weisberg S. An R companion to applied regression. 3rd ed. Los Angeles: Sage; 2019.

Friendly M. Mosaic displays for multi-way contingency tables. J Am Stat Assoc. 1994:89:190-200.

Friendly M. Working with categorical data with $\mathrm{R}$ and the vcd and vcdExtra packages. Toronto: York University; 2013.

Friendly M, Meyer D. Discrete data analysis with $\mathrm{R}$ : visualization and modeling techniques for categorical and count data. London: Chapman and Hall/ CRC; 2015.

Gorenzel WP, Salmon TP. Characteristics of American crow urban roosts in California. JWildl Manage. 1995;59:638-45.

Hamilton NE, Ferry M. ggtern: ternary diagrams using ggplot2. J Stat Soft. 2018;87:1-17

Hong Kong Observatory. Climate of Hong Kong. 2020. https://www.hko.gov. hk/en/cis/climahk.htm\#. Accessed 09 Oct 2020.

Jaggard AK, Smith N, Torpy FR, Munro U. Rules of the roost: characteristics of nocturnal communal roosts of rainbow lorikeets (Trichoglossus haematodus, Psittacidae) in an urban environment. Urban Ecosyst. 2015;18:489-502.

Jenni L. Microclimate of roost sites selected by wintering Bramblings Fringilla montifringilla. Ornis Scand. 1991;22:327-34.

Kassambara A, Mundt F. factoextra: extract and visualize the results of multivariate data analyses. R package version 1.0.5. 2017.

Khadraoui M, Toews DPL. The influence of environmental cues and anthropogenic activity on roost departure times in the Northwestern Crow (Corvus caurinus). Wilson J Ornithol. 2015;127:739-46.

Laughlin AJ, Sheldon DR, Winkler DW, Taylor CM. Behavioral drivers of communal roosting in a songbird: combined theoretical and empirical approach. Behav Ecol. 2014;25:734-43.

Lee S-H, Lee K-S, Jin W-C, Song H-K. Effect of an urban park on air temperature differences in a central business district area. Landsc Ecol Eng. 2009:5:183-91.

Le Roux C. Nocturnal roost tree, roost site and landscape characteristics of Carnaby's Black-Cockatoo (Calyptorynchus latirostris) on the Swan Coastal Plain. Master's Thesis. Perth: Edith Cowan University; 2017.

Leven MR, Corlett RT. Invasive birds in Hong Kong, China. Ornithol Sci. 2004:3:43-55.

Maechler M, Rousseeuw P, Struyf A, Hubert M, Hornik K. cluster: cluster analysis basics and extensions. R package version 2.1.0. 2019.

McKechnie AE, Körtner G, Lovegrove BG. Thermoregulation under semi-natural conditions in speckled mousebirds: the role of communal roosting. Afr Zool. 2006;41:155-63.
McKechnie AE, Lovegrove BG. Avian facultative hypothermic responses: a review. Condor. 2002;104:705-24.

Meyer D, Zeileis A, Hornik K. The strucplot framework: visualizing multi-way contingency tables. J Stat Soft. 2006;17:1-14.

Meyer D, Zeileis A, Hornik K. vcd: visualizing categorical data. R package version 1.4.4. 2017.

Mok SY, So WY, Lee WH, Cheng WW. An estimation of the current population size of the Yellow-crested Cockatoo (Cacatua sulphurea) in Hong Kong. Hong Kong Biodiversity. 2012;22:16-8.

Moore JE, Switzer PV. Preroosting aggregations in the American crow, Corvus brachyrhyncos. Can J Zool. 1998;76:508-12.

Neo ML. A review of three alien parrots in Singapore. Nat Singap. 2012;5:241-8.

Peh KS, Sodhi NS. Characteristics of nocturnal roosts of house crows in Singapore. J Wildl Manage. 2002;66:1128-33.

Pérez-Enciso M, Tenenhaus M. Prediction of clinical outcome with microarray data: a partial least squares discriminant analysis (PLS-DA) approach. Hum Genet. 2003;112:581-92.

Planning Department. Land utilization in Hong Kong 2019. Government of Hong Kong SAR, China. 2020. https://www.pland.gov.hk/pland_en/info_ serv/statistic/landu.html. Accessed 09 Oct 2020.

R Core Team. R: A language and environment for statistical computing. Vienna, Austria: R Foundation for Statistical Computing; 2018.

Rohart F, Gautier B, Singh A, Lê Cao K. mixOmics: an R package for 'omics feature selection and multiple data integration. PLoS Comput Biol. 2017:13:e1005752.

Saiyad S, Soni VC, Radadia B. Roosting site selection by Indian House Crow (Corvus splendens). Int J Fauna Biol Stud. 2017;4:10-3.

Sonerud GA, Hansen H, Smedshaug CA. Individual roosting strategies in a flock-living bird: movement and social cohesion of hooded crows (Corvus corone cornix) from pre-roost gatherings to roost sites. Behav Ecol Sociobiol. 2002:51:309-18.

Thévenot EA, Roux A, Xu Y, Ezan E, Junot C. Analysis of the human adult urinary metabolome variations with age, body mass index, and gender by implementing a comprehensive workflow for univariate and OPLS statistical analyses. J Proteome Res. 2015;14:3322-35.

Wang S. Establishment of an introduced population of critically endangered Yellow-crested Cockatoo (Cacatua sulphurea) in Hong Kong. Doctoral Thesis. Hong Kong SAR, China: The Chinese University of Hong Kong; 2020

Wang S, Ho Y, Chu LM. Diet and feeding behavior of the critically endangered Yellow-crested Cockatoo (Cacatua sulphurea) in a non-native urban environment. Wilson J Ornithol. 2018:130:746-54.

Ward P, Zahavi A. The importance of certain assemblages of birds as "information-centres" for food-finding. Ibis. 1973;115:517-34.

Wu S, Guo J. PLS and OPLS discriminatory analyses on political sustainability in Taiwan. Sustainability. 2018;10:60.

Yap CA, Sodhi NS, Brook BW. Roost characteristics of invasive mynas in Singapore. J Wildl Manage. 2002;66:1118-27.

Zahavi A. Function of pre-roost gatherings and communal roosts. Ibis. 1971;113:106-9.

Ready to submit your research? Choose BMC and benefit from

- fast, convenient online submission

- thorough peer review by experienced researchers in your field

- rapid publication on acceptance

- support for research data, including large and complex data types

- gold Open Access which fosters wider collaboration and increased citations

- maximum visibility for your research: over $100 \mathrm{M}$ website views per year

At BMC, research is always in progress.

Learn more biomedcentral.com/submissions 